\title{
Pulmonary metastasectomy in colorectal cancer: PulMiCC and future trials
}

\author{
Norman R. Williams ${ }^{1}$, Fergus Macbeth ${ }^{2}$, Tom Treasure $^{3} \wedge$ \\ ${ }^{1}$ Surgical and Interventional Trials Unit, University College London, London, UK; ${ }^{2}$ Centre for Trials Research, Cardiff University, Cardiff, UK; \\ ${ }^{3}$ Clinical Operational Research Unit, University College London, London, UK
}

Correspondence to: Tom Treasure. Clinical Operational Research Unit, University College London, London, WC1H 0BT, UK.

Email: tom.treasure@gmail.com.

Comment on: Taylor M, Abah U, Shah R. A review of interventional treatments for colorectal lung metastases: is it time for a change in practice? Quant Imaging Med Surg 2020;10:1413-17.

Submitted Jun 18, 2020. Accepted for publication Jul 03, 2020.

doi: 10.21037/qims-20-774

View this article at: http://dx.doi.org/10.21037/qims-20-774

Marcus Taylor and colleagues provide an excellent summary of the present situation with respect to the treatment of lung metastases from colorectal cancer (CRC), but we don't agree with the specific research question they propose to test in a randomized trial. They write:

'In conclusion, there remains very little bigh-quality evidence demonstrating the benefit of any form of intervention in this patient group and hence a controlled trial comparing overall survival between patients undergoing surgical metastasectomy, SABR or RFA for biopsy-proven metastatic colorectal cancer is required to address the question of which modality provides superior outcomes in this cohort of patients.' (1).

In their review they found no good evidence for benefit of any of these local treatments of metastases and so, we contend, it would be irrational to do a randomized controlled trial (RCT) making a comparison between any of them. Unless you know there is benefit, which requires a non-interventional arm, all you might show is which does less harm. Otherwise you would, unknowingly, interpret the difference as a greater benefit.

The paper by Hasegawa on which Taylor et al. comment includes 70 patients with a predominance of favorable features for longer than average survival. Ten departments took more than 6 years to select and accrue these patients and so it is likely that they were highly selected. But we are provided with no denominator. In $79 \%$ of them the prognostic indicators were good: metastases were solitary, the mean size was $1 \mathrm{~cm}, 66 \%$ of had no CEA elevation, and there was a mean interval since primary CRC resection of more than 3 years (2). As Taylor et al. observe there were also very few histological confirmations. The 3 -year survival was $84 \%$. At the same time point, survival in the non-metastasectomy arm of the RCT Pulmonary Metastasectomy in Colorectal Cancer (PulMiCC) was $70 \%$ (3). These were patients eligible for metastasectomy but not as highly selected as in Hasegawa's RFA report. The difference in survival may simply be due to higher selection and a better prognosis.

The belief in the clinical benefit of surgical lung metastasectomy has been entirely based on an assumption that 5-year survival would be zero, or close to it, if the lung metastases had not been removed (4). This assumption has been robustly challenged by the STS working group on lung metastasectomy. They could find no evidence to support this belief among over 1,000 papers. They state emphatically that the assumption of zero mortality is not supported by the literature (5).

The zero belief was somewhat modified in the systematic review by Gonzalez et al. who wrote that survival is 'worse than $5 \%$ ' (6). In support they cited a paper, from more than

^ ORCID: 0000-0001-9358-7610。 


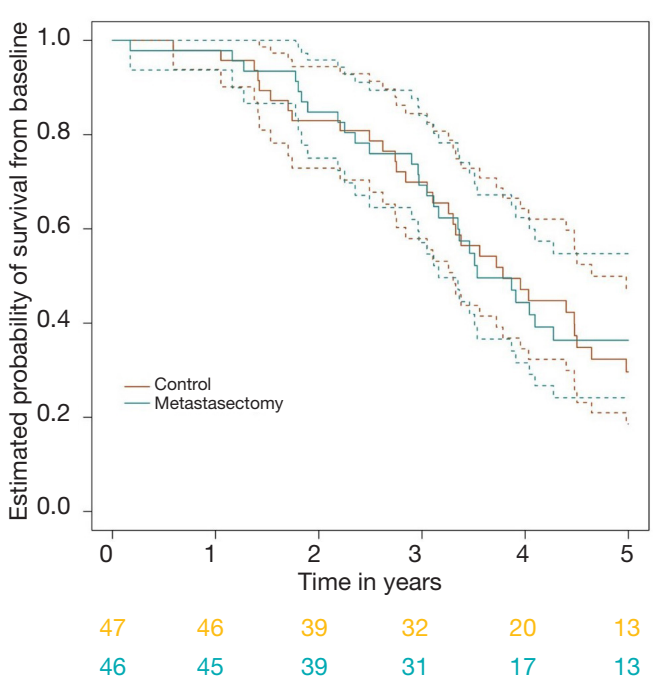

Figure 1 The Kaplan-Meier survival graph from PulMiCC RCT (3). No survival difference was found between the two well matched arms of the trial throughout 5 years of follow up. RCT, randomized controlled trial.

30 years ago, about biochemical modulation of fluorouracil treatment in CRC (7). The patients had very advanced disease and bore no resemblance to those currently considered for local interventions. Nevertheless, this false assumption has been restated in a response to recent guidelines, without reference to any evidence (8).

PulMiCC has been updated since the reference given by Taylor and colleagues, with results in 93 randomized patients (3). The median survival after metastasectomy was 3.5 years compared with 3.8 years for controls. The hazard ratio was 0.93 (95\% CI: $0.56,1.56)$. The survival curves of the two groups run close to each other (Figure 1). If wishful thinking, or the eye of faith, see a difference beyond 4 years, it is possibly there. We know that colleagues recall occasional long-lived patients after surgical metastasectomy, and these may have had a truly solitary metastasis removed, resulting in 'cure', but in nearly all cases the disease is systemic. We stand by our statement 'our findings are compatible with the belief that some patients, in whom lung metastases are truly the only residue of their colorectal cancer, may survive long term as a direct result of metastasectomy', not 'pulmonary metastasectomy is likely to convey benefit', a statement wrongly attributed to us (1).

CRC lung metastases are asymptomatic and if left alone, usually remain so. Death from CRC is rarely related to lung metastases. Most patients go on to die, with the same pattern of disease, and the same time course, as if they had kept their lung metastases. If there is a benefit, its magnitude is not yet known but we do know a lot about which features favor survival and on which case selection is based (6). Unless there is a control group, claims for better survival may be simply selection bias. Observing patient progress over a period of months while they are having chemotherapy introduces immortal time bias, because it is therefore perfectly possible to pick the patients naturally likely to survive for another 3 years. The relatively flat survival curve over the first 2-3 years in Hasegawa's figure 3 illustrates this bias (2).

There are now three RCTs with control groups including patients with CRC metastases showing much better than expected survival. The two confined to CRC metastases, EORTC 40004 and PulMiCC, provide 106 patients randomly assigned to not have local treatment. In neither trial were patients as favorable as the highly selected subset that Hasegawa and colleagues recruited for their single arm study. Nonetheless, the 5 -year survival in the pooled 106 patients was $30 \%$ (95\% CI: $21 \%, 40 \%$ ) (9). It is clear that the near-zero assumption, and the more moderate $<5 \%$, are false (4).

It is timely to bring this question to the attention of radiologists involved in quantitative imaging. They are the first to know that an asymptomatic CRC patient has lung metastases. Radiologists should be central to any future trials of lung metastasectomy, identifying patients before they are told by well-meaning team members that the metastases should be removed, thus destroying equipoise and defeating a randomized trial. Informed trial recruitment should be provided not by clinicians with a vested interest, but by trial staff (10). Radiologists could play a pivotal role in triggering the first steps.

\section{Acknowledgments}

Funding: None.

\section{Footnote}

Conflicts of Interest: All authors have completed the ICMJE uniform disclosure form (available at http://dx.doi. org/10.21037/qims-20-774). The authors have no conflicts of interest to declare.

Open Access Statement: This is an Open Access article distributed in accordance with the Creative Commons Attribution-NonCommercial-NoDerivs 4.0 International 
License (CC BY-NC-ND 4.0), which permits the noncommercial replication and distribution of the article with the strict proviso that no changes or edits are made and the original work is properly cited (including links to both the formal publication through the relevant DOI and the license). See: https://creativecommons.org/licenses/by-nc-nd/4.0/.

\section{References}

1. Taylor M, Abah U, Shah R. A review of interventional treatments for colorectal lung metastases: is it time for a change in practice? Quant Imaging Med Surg 2020;10:1413-17.

2. Hasegawa T, Takaki H, Kodama H, Yamanaka T, Nakatsuka A, Sato Y, Takao M, Katayama Y, Fukai I, Kato T, Tokui T, Tempaku H, Adachi K, Matsushima Y, Inaba Y, Yamakado K. Three-year survival rate after radiofrequency ablation for surgically resectable colorectal lung metastases: a prospective multicenter study. Radiology 2020;294:686-95.

3. Milosevic M, Edwards J, Tsang D, Dunning J, Shackcloth M, Batchelor T, Coonar A, Hasan J, Davidson B, Marchbank A, Grumett S, Williams NR, Macbeth F, Farewell V, Treasure T. Pulmonary Metastasectomy in Colorectal Cancer: updated analysis of 93 randomized patients - control survival is much better than previously assumed. Colorectal Dis 2020. [Epub ahead of print]. doi:10.1111/codi.15113.

4. Macbeth F, Fallowfield L. The myth of pulmonary metastasectomy. Br J Cancer 2020;123:499-500.

5. Handy JR, Bremner RM, Crocenzi TS, Detterbeck FC, Fernando HC, Fidias PM, Firestone S, Johnstone CA,

Cite this article as: Williams NR, Macbeth F, Treasure T. Pulmonary metastasectomy in colorectal cancer: PulMiCC and future trials. Quant Imaging Med Surg 2020;10(11):2215-2217. doi: 10.21037/qims-20-774
Lanuti M, Litle VR, Kesler KA, Mitchell JD, Pass HI, Ross HJ, Varghese TK. Expert consensus document on pulmonary metastasectomy. Ann Thorac Surg 2019;107:631-49.

6. Gonzalez M, Poncet A, Combescure C, Robert J, Ris HB, Gervaz P. Risk factors for survival after lung metastasectomy in colorectal cancer patients: a systematic review and meta-analysis. Ann Surg Oncol 2013;20:572-9.

7. Poon MA, O'Connell MJ, Moertel CG, Wieand HS, Cullinan SA, Everson LK, Krook JE, Mailliard JA, Laurie JA, Tschetter LK. Biochemical modulation of fluorouracil: evidence of significant improvement of survival and quality of life in patients with advanced colorectal carcinoma. J Clin Oncol 1989;7:1407-18.

8. Beavis HJ, Buchan K. Re: Colorectal Cancer: summary of NICE guidance. BMJ 2020. Available online: https://www. bmj.com/content/368/bmj.m461/rr-0

9. Ruers T, Van Coevorden F, Punt CJ, Pierie JE, BorelRinkes I, Ledermann JA, Poston G, Bechstein W, Lentz MA, Mauer M, Folprecht G, Van Cutsem E, Ducreux M, Nordlinger B; European Organisation for Research and Treatment of Cancer (EORTC); Gastro-Intestinal Tract Cancer Group; Arbeitsgruppe Lebermetastasen und tumoren in der Chirurgischen Arbeitsgemeinschaft Onkologie (ALM-CAO); National Cancer Research Institute Colorectal Clinical Study Group (NCRI CCSG). Local treatment of unresectable colorectal liver metastases: results of a randomized phase II trial. J Natl Cancer Inst 2017;109:djx015.

10. Treasure T, Baum M. An approach to randomization into surgical clinical trials. Br J Surg 2017;104:11-2. 